\title{
Health in the transition from childhood to adolescence: the 11-year follow-up of the 1993 Pelotas (Brazil) birth cohort study
}

This thematic issue is intended to tell an 11-year story. In 1993, in Pelotas, Rio Grande do Sul State, Brazil, 4,452 babies were born that became the city's cohort of life births for that year. The mothers were interviewed and the newborns were examined, weighed, and measured, among other procedures. From that moment on, a bond was formed between us the researchers - and this legion of families.

Beginning that year we followed a randomly selected subsample of the cohort at different ages. At each follow-up visit the parents and children asked us how we had located them, why specifically them, and what we intended to do with the information. We explained the importance of the visits, how the information could help us understand specific childhood events, and the potential effects at later ages.

As in every story there were different special moments, and "all of a sudden" our "kids" were becoming teens: they were 11 years old! We had always wanted to follow all of them, and at the time we had the necessary resources. But since they were no longer children, our approach had to change. We knew that by now the questions and challenges would often come from the kids themselves rather than their mothers, and the team had to be prepared for this new reality.

We were also aware that one phase had finished, and we were extremely curious about what we would encounter in that age of transition, namely 11 years. We prepared confidential questionnaires for the adolescents themselves (it was clear to us that not everything could be said in the mother's presence), plus questionnaires for the mothers, since the adolescents would tend not to know the answers to some questions (which only the parents knew).

And so our story proceeded... Like "detectives", using countless strategies and juggling acts (described in the "Methods" article in this thematic issue), we managed to locate $87.5 \%$ of the original cohort. We were really happy, given the families' extensive mobility.

Due to the reality of Brazilian teenagers, we studied not only their nutritional status and eating habits, but also fiber and intake, weight loss dieting, and physical activity, since their prevailing aesthetic "standard", especially for girls, appeared to feature a slim appearance. Within this context of 11 years, an age of experimentation and change, we asked about alcohol consumption, use of medicines, wellness, and problems with attention and hyperactivity. In the attempt to identify possible risk markers for chronic diseases in adulthood, we investigated blood pressure, pulse rate, and hospitalizations. In a subsample, we also evaluated the adolescents' oral health.

The results of the story are told in different articles in this thematic issue. Rather than giving away details in the Editorial, we recommend that readers enjoy the story themselves.

As we said, this is one stage in the story of our 1993 Pelotas birth cohort. Other stories are certain to be told after the next visits to our "big family", which has been followed since birth!

Ana M. B. Menezes

Programa de Pós-graduação em Epidemiologia, Universidade

Federal de Pelotas, Pelotas, Brasil.

anamene@terra.com.br

Cora Luiza Araújo

Faculdade de Nutrição, Universidade Federal de Pelotas

Pelotas, Brasil. Programa de Pós-graduação em Epidemiologia

Universidade Federal de Pelotas, Pelotas, Brasil.

cora.araujo@terra.com.br

\section{Pedro C. Hallal}

Programa de Pós-graduação em Epidemiologia, Universidade

Federal de Pelotas, Pelotas, Brasil.

Programa de Pós-graduação em Educação Física, Universidade

Federal de Pelotas, Pelotas, Brasil.

prchallal@gmail.com 